\title{
Seismicity Management Using Tight Slot Blasting for Stress Control at Mt Charlotte Mine
}

\author{
P.A. Mikula Kalgoorlie Consolidated Gold Mines Pty Ltd, Australia \\ G. Sharrock AMC Consultants Pty Ltd, Australia \\ M. Lee AMC Consultants Pty Ltd, Australia \\ E. Kinnersly Kalgoorlie Consolidated Gold Mines Pty Ltd, Australia
}

A new procedure for seismicity management, Tight Slot Blasting, is proposed. The technique achieves stope-scale destressing by the precise blasting of a slot, creating a tightly packed zone of broken rock designed to destress the rockmass, allow controlled and dampened shearing on critical geologic structures, and provide an assured energy absorption and shear arrest mechanism. The key elements are tight firing (low blast expansion void) and rapid firing (electronic detonation). The procedure is aimed to meet the challenge of the seismic-prone ROB5 orebody remnant. ROB5 seismicity is a function of direction of mining, the geometry of large rock wedges, and offsets on some geologic structures where they are intersected by others. Four previous large seismic events were back-analysed using Map3D numerical modelling to obtain a calibrated model to study Tight Slot Blasting options. Model forecasts indicated significant reductions in expected maximum seismic event magnitudes, representing $29 \%$ to $82 \%$ reductions in energy release. It is hoped to trial the technique in the near future.

\section{INTRODUCTION}

Fault-shear seismicity is considered possible when mining the ROB5 orebody remnant at Mt Charlotte mine. The original mining plans for ROB5 were modified during the open stoping phase, resulting in the present situation where a remnant located below the original stope is highly stressed and seismic-prone. However, the remnant is an attractive resource, about 667,000 tonnes at $3.7 \mathrm{~g} / \mathrm{t}$, so options for reducing or managing the seismic risk were sought.

Building on the understanding of seismicity gained at $\mathrm{Mt}$ Charlotte over the last 10 years (Mikula \& Lee, 2002) a new procedure for seismicity management, Tight Slot Blasting (TSB) was formulated by KCGM and AMC Consultants (AMC, 2004). This consists of controlled tight blasting of a narrow slot along the length of the orebody. The TSB slot is not a conventional mining slot. It is the precisely designed and executed blasting of a slot creating a tightly packed zone of broken rock, positioned to destress the rockmass and allow controlled and dampened shearing on the critical geologic structures. The outcome is stress control for subsequent mining, rather than violent strain energy release on the structures. It is hoped to trial the method at Mt Charlotte in the near future.

TSB is a destressing technique, and is an alternative to conventional destress blasting or other approaches such as hydraulic pressurization. TSB differs from the other techniques in that it reduces stresses by incrementally removing the rock and immediately replacing it as a less stiff rockfill material.

This paper discusses:

- Previous ROB5 stoping.

- Definition and application of the TSB technology.

- Back-analysis of several seismic events to validate a numerical model.

- Forecasting seismicity using numerical modelling, comparing cases with and without TSB.

Seismic event magnitudes in this paper are Richter magnitudes unless stated otherwise.

\section{SHORT HISTORY OF ROB5 STOPING}

\subsection{The ROB5 Faults and R-Shears}

The ROB5 stoping block is bound by two sub-vertical northeast striking faults - Reward Fault on the northern end and Maritana Fault on the south. Shea Fault dipping at $45^{\circ}$ to the west cuts through the stope. Seven R-shears (called R2, R3, R3A, R4, R5, R6 and R7) are sub-parallel to Reward Fault, and transect the stope block at $20 \mathrm{~m}$ to $50 \mathrm{~m}$ intervals (Fig 1). The R-shears are not as well developed as the major faults. They appear as one or several thin close and sub-parallel semi-continuous surfaces (Fig 2), which are variably offset by other similar shears. They show undulations with semiamplitude of up to $5 \mathrm{~m}$ over a distance of $40 \mathrm{~m}$. R-shears are exposed to nearly the maximum shear stress developed in the prevailing geometry and stress field.

R-shears have numerous minor offsets at intersections with Charlotte's other common set of structures that dip at $45^{\circ}$ to the west. Offset locations and styles cannot be easily determined, and they can control the ease of shearing and seismicity on Rshears. Offsets, in combination with undulations, can cause locking on the R-shears, and shear may not be possible even in a slip-favourable stress state (Fig 3). Energy is stored on the structures, and seismic response occurs if shearing becomes both mechanically and kinematically possible. The shearing mechanism is assumed to be the breakage of asperities as described in Gibowicz and Kijko (1994).

\subsection{Stope Design and History}

ROB5 was mined as one large open stope, rather than several smaller stopes and minimal permanent pillars. The single stope recovered more ore, and avoided highly stressed meta-stable pillars with the chance of failure by shearing on structures.

ROB5 (21 to 24 Level) began in 1990 as an open stope, starting at the widest northern section, and it immediately experienced high stress slabbing in the stope backs, and occasional seismicity. The northern advance of the stope was prematurely terminated about $30 \mathrm{~m}$ short of intersecting Reward Fault. Due to the wide span, the stress-induced overbreak in the stope backs extended to a stable arch up to 


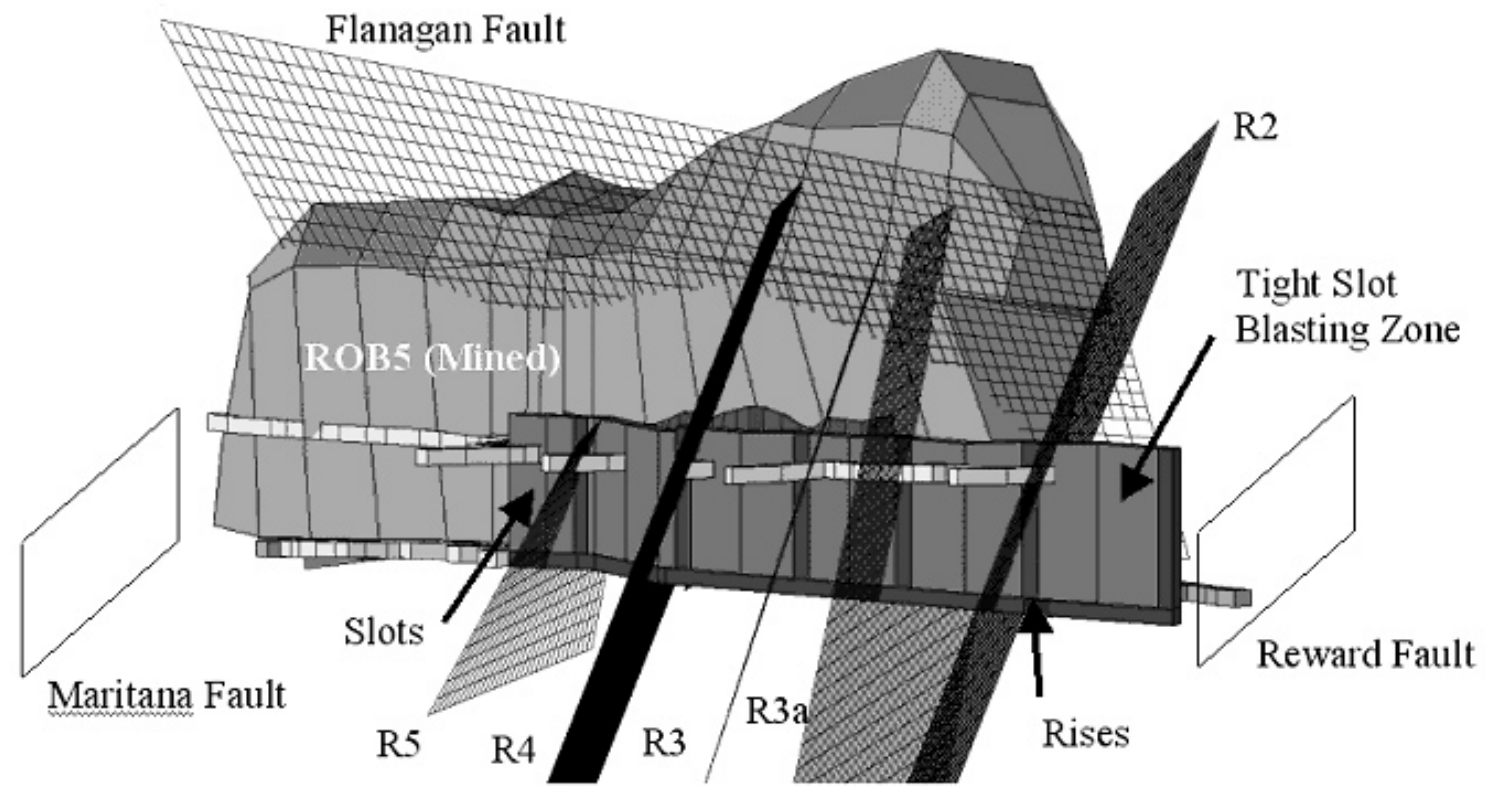

FIG. 1 ROB5 Tight Slot Blasting Zone, looking SW - creation of the destressed zone prior to mining

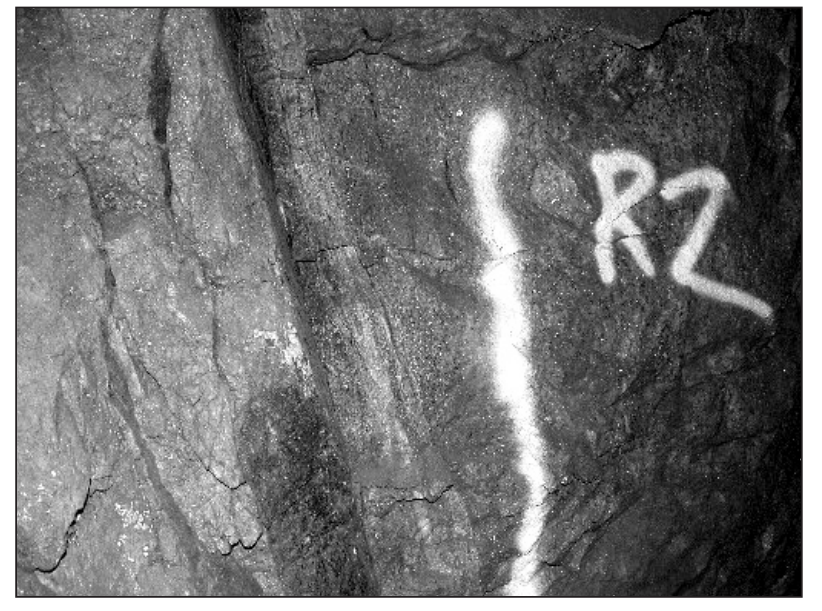

FIG. 2 R2-shear on 24 Level: Inspection revealed no sign of any slip having occurred on this structure

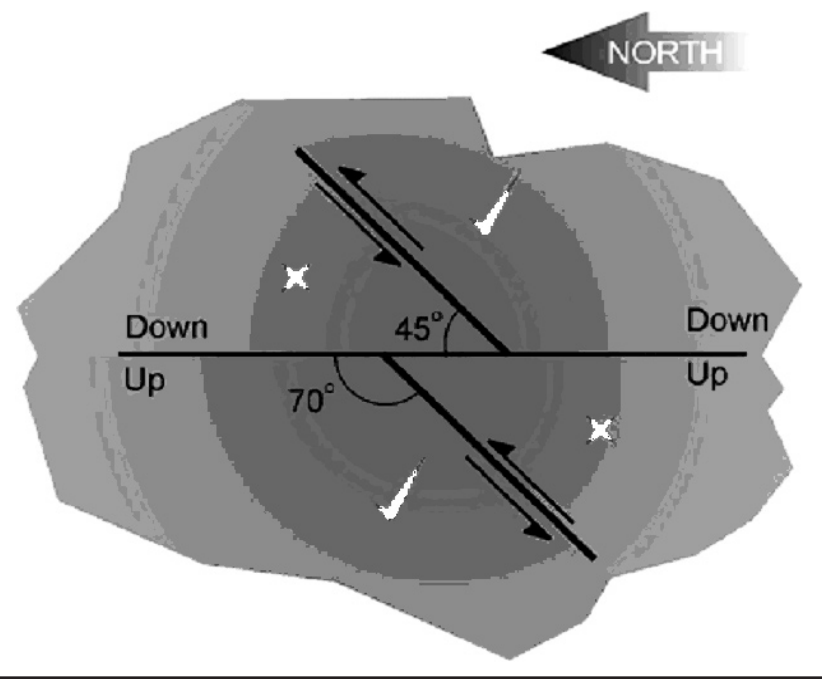

FIG. 3 Structural configuration for satisfaction of fault-slip kinematics
$50 \mathrm{~m}$ above the design backs.

Meanwhile, the orebody became bigger. Exploration drilling had defined ore reserves further south and below the original stope. When the southward advancing stope front drew level with Cassidy Shaft (in Nov 1992), a slot was mined down to 25 Level, and the stope again progressed southwards but now included 25 Level mining. The drop-down slot was positioned very close to R5-shear, and was accompanied by rock noise. ROB5 was completed to the southern end in Oct 1994. The north end of the stope was used to dispose of development waste.

With primary mining completed, ore remained below the northern two-thirds of the primary stope. New 25 Level development was mined for proposed SLC retreat of the 24-25 level ore from south to north. However, the first new 25 Level production blast (Jan 1995) was associated with a concurrent large seismic event (Richter magnitude 2.8) involving slip on R5-shear. Further stoping was abandoned. Results from the back analysis of this event are presented later in this paper.

Intermediate 24A Level development was then mined, to attempt longitudinal SLC retreat of the 24-25 Level back towards a central waste pillar. However this development exposed about a $30 \mathrm{~m}$ length of R3-shear, which was the focus of major seismicity in March 1997. The R3-shear events are also back-analysed below. This mining strategy was also abandoned.

\section{SEISMICITY BACKGROUND}

Significant seismicity at Mt Charlotte is often associated with shearing on major structures. Where these structures intersect or pass close to stoping blocks, designs have been modified to reduce perceived exposure to seismic risk. In some cases this has meant smaller stopes or early termination of production.

There have been positive experiences at Mt Charlotte with both preconditioning and destress slotting. The I1 stope pillar was preconditioned in 1995 with the aim of decreasing the seismic risk. This was followed by a small C4 destressing project in 1999. The destressing option is now a standard proactive tool to reduce and manage seismicity. 
The Mt Charlotte PSS seismic monitoring system became operational in May 1994, unfortunately after the first ROB5 stope was completed. Figures 4 and 5 summarise the available ROB5 seismic data for the region of interest (24 to 25 Level) using MSRAP output (Hudyma et al., 2003).

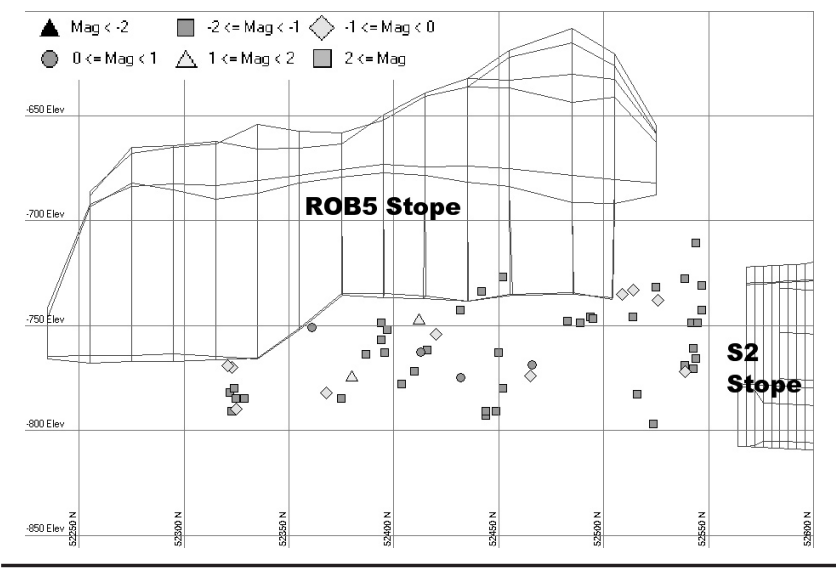

FIG. 4 Long-section view showing the ROB5 remnant cluster of seismic event locations, with events coded by local magnitude (refer section 9.2 for a local to Richter magnitude conversion)

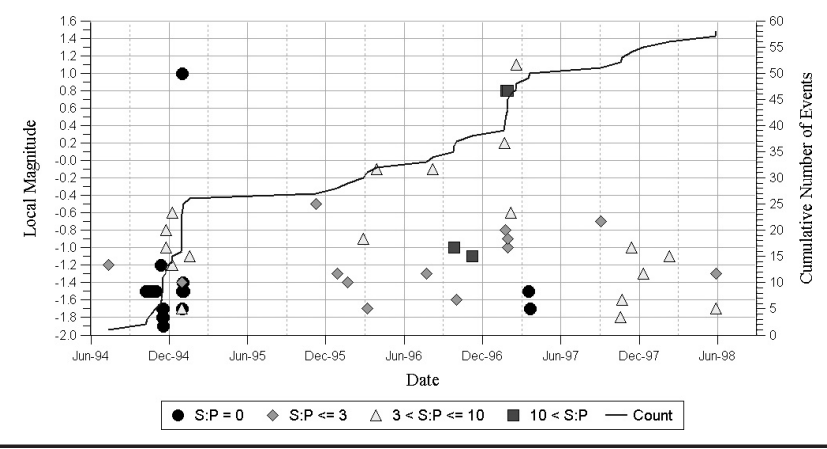

FIG. 5 Time-magnitude plot of the events shown in Figure 4, including the R5, R3 and R4 events discussed in Section 10 (events coded by S:P energy ratio)

ROB5 seismic behaviour was an enigma. Significant seismicity did not occur when the stope was mined from north to south, despite mining through several R-shears. The large R5 event came with the first south-to-north firing. Seismicity in ROB5 is now understood to be a function of:

- The main structures (R-shears and $45^{\circ}$ west-dippers)

- The direction of mining (N-S or S-N)

- The situation (east wall or west wall)

The four possible permutations are listed in Table 1. Only one of them suggests high seismicity: i.e. mining south to north, as had been experienced.

This demonstrates the behaviour of a two-structure system (quite different to single-structure systems which are rare in the real world). The ROB5 two-structure system is a threedimensional entity. These wedges occur between moderate west-dipping and steep northwest dipping release structures, an arrangement that does not have symmetry with respect to stoping. Modelling realistic behaviour of single-structure systems is tricky enough, let al.one multi-structure systems.
TABLE 1 ROB5 mining permutations - rock wedges are defined by the intersection of 450 west-dipping structures (e.g. Shea fault) with very steep northwest dipping structures (R-shears)

\begin{tabular}{ll}
\hline North to south mining & South to north mining \\
\hline In stope west wall: & In stope west wall: Significant \\
Low seismicity. Shearing & seismicity. Mining occasionally \\
and loosening on R- & isolates and allows rapid \\
shears happens gradually & (violent) shearing of rock \\
as stoping advances South. & wedges bounded by R-shears. \\
Blasts gradually put rock & This is the classic soft \\
wedges into stress shadow. & abutment. No impediment to \\
Wedges move gradually. & shearing and opening on both \\
& R-shears and 45 west-dippers. \\
& The normal load decreases \\
& during the event (a strain- \\
& softening event). \\
\hline In stope east wall: & In stope east wall: \\
Low seismicity. Mining isolates & Low seismicity. Gradual \\
small loosened wedges high & loosening of wedges above \\
in the east wall. Movement by & $45^{\circ}$ west-dippers, with gradual \\
gravity sliding on Shea. & shearing on R-shears. Shea \\
& Fault forms a release plane \\
& for small rock wedges high up \\
& in the wall. Blasting gradually \\
& puts rock wedges into stress \\
& shadow. Wedges move \\
& gradually. \\
\hline
\end{tabular}

TABLE 2 Intact rock and rockmass properties

\begin{tabular}{|c|c|c|c|c|c|}
\hline \multicolumn{2}{|c|}{$\mathrm{UCS}_{50}(\mathrm{MPa})$} & \multirow{2}{*}{$\begin{array}{c}\begin{array}{c}\text { UCS } \\
\text { in situ } \\
\text { (MPa) }\end{array} \\
\sim 80 \text { to } 90\end{array}$} & \multirow{2}{*}{$\begin{array}{c}\mathbf{v} \\
0.34\end{array}$} & \multirow{2}{*}{$\begin{array}{c}\mathrm{E} \\
(\mathrm{GPa}) \\
84\end{array}$} & \multirow{2}{*}{$\begin{array}{c}\text { *Mass } \\
\text { strength } \\
\text { (MPa) }\end{array}$} \\
\hline $\begin{array}{l}\text { Dolerite Unit } 7 \\
\text { (hangingwall) }\end{array}$ & 152 & & & & \\
\hline $\begin{array}{l}\text { Dolerite Unit } 8 \\
\text { (ROB5 stope) }\end{array}$ & 177 & $\sim 80$ & 0.22 & 65 & \multirow[t]{2}{*}{$\begin{array}{c}\sigma_{1}= \\
60+2 \sigma_{3}\end{array}$} \\
\hline $\begin{array}{l}\text { Dolerite Unit } 9 \\
\text { (footwall) }\end{array}$ & 167 & $\sim 80$ & 0.18 & 69 & \\
\hline
\end{tabular}

* Derived from a back-analysis of the I1 Rib Pillar monitoring (Mikula and Lee, 2002).

\section{ROCK PROPERTIES AND STRESS FIELD}

Reliable intact rock and rockmass properties for Mt Charlotte are available (Table 2) with further information in Mikula and Lee (2002).

Estimates of in situ peak and residual shear strengths for typical Charlotte structures have also been developed from back-analysing normal and shear stresses on structures near in situ stress measurements (Lee and Fotakis, 1992). The Mohr-Coulomb shear strengths are: Peak $2 \mathrm{MPa}, 21.5^{\circ}$, Residual $1 \mathrm{MPa}, 16.5^{\circ}$.

Seven in situ rock stress measurements have been done at Charlotte. The measurement done on 24 Level close to the area of interest was used for the ROB5 modelling. The farfield stress tensor defined for the project at the TSB depth of $760 \mathrm{~m}$ BD was:

$\sigma_{1} 64 \mathrm{MPa}$, horizontal north-south

$\sigma_{2} 35 \mathrm{MPa}$, sub-horizontal dip down to the west

$\sigma_{3} 22 \mathrm{MPa}$, subvertical.

The major principal stress directly beneath the bottom abutment of ROB5, i.e. in the remnant, is east-west. 


\section{TIGHT SLOT BLASTING (TSB) CONCEPT}

\subsection{Two Critical TSB Outcomes}

TSB is the controlled tight blasting of a precisely designed slot, creating a tightly packed broken zone of rock, positioned to destress the rockmass and allow controlled and dampened shearing on critical geologic structures. The outcome is stress control (enforced stress shadow) for subsequent mining, and gradual rather than violent strain energy release on the structures. TSB manages fault-shear seismicity by ensuring two critical outcomes: firstly staged energy release, and secondly an assured energy absorption and shear-arrest mechanism.

Staged energy release is important. Energy release from the rockmass in the stope area is controlled by only allowing gradual shear movement on the structure (at a chosen time, over small areas and for small shear displacements). An analogy is a big tree that is leaning and likely to topple in the next storm. It is better to cut it down in stages, ideally when there is no wind, rather than felling it in one operation. The amount of energy released is a function of:

- The shear displacement.

- The rate or speed of energy release.

- The stress-drop, from peak to residual shear strength.

- The area of slip, possibly limited by features such as offsets and bridges.

- The type of irrecoverable shear (strain hardening means less energy released).

An assured energy absorption and shear-arrest mechanism is also vital. Energy must be absorbed from the system by ensuring that significant work is done by the rockmass as it attempts to move, thus arresting the shearing. Arrested shear is hazardous if the arresting mechanism (e.g. a rock bridge or offset) can fail. TSB uses tightly-packed broken rock to rapidly arrest shear, an assured control option. Equilibrium is reached when the rockfill load-deformation curve meets the local mine stiffness curve.

It would be nice to know how all the above variables were related, and then be able to confidently model and forecast the size of events. However, current understanding is inadequate to confidently achieve this. The proposed TSB method targets three of the above items: shear displacement, area of slip, and speed of energy release.

\subsection{TSB and Conventional Slotting Compared}

The TSB concept slot differs from a conventional slot in two critical ways:

- Tight firing. The slot blast void must be small so that the fired rock becomes very tightly packed, almost frozen. The swell factor may be only about 115 $-125 \%$ of the blasted rock volume. It is anticipated that the blasted rock product will be tightly packed, interlocked, and difficult or unable to be bogged. This interlocked product will obstruct the free movement of the surrounding rockmass, yet be a mechanically softer zone for incremental destressing of R-shears. The blast design must ensure at least a minimum degree of damage.

- Rapid firing (electronic detonation). Electronic detonation will be used to mine the slot rapidly, say in less than $1000 \mathrm{msec}$. This is necessary to ensure that the slot void is filled quicker than the surrounding rockmass can move significantly towards a new equilibrium. The quicker the slot is fired, the sooner the surrounding rockmass has to exert work on the blasted product in order to achieve closure.

Historically, if major seismicity happens to occur with blasts at Mt Charlotte, it is observed to initiate usually 1 to 3 seconds after commencement of the blast, but in three instances the delay was only 0.1 seconds. This suggests the slot blast must be completed in well under 1 second, or perhaps in episodes each much shorter than 1 second. This is perhaps the ultimate in "just-in-time" rockfilling.

There are two interesting uncertainties with rapid firing:

- Whether there is a speed limit - too rapid detonation could result in too rapid stressing of the rock just ahead of the slot face, causing it to fail seismically.

- Whether electronic detonation, by reducing both peak and low frequency vibrations, may also contribute to reducing seismic response.

If an event occurs during slotting, the dynamic stress wave will pass the slot creating an impulse on the slot rockfill. The resistance of the rockfill to compression (the bulk stiffness) is untested but may be considerably higher under impulse rather than static conditions. This should restrain or dampen the seismic accelerations and displacements.

\section{DESIGN OPTIONS FOR ROB5 REMNANT}

TSB has been selected for mining the ROB5 remnant, because it can potentially reduce seismic risk better than the following alternatives:

- Blasthole fans aligned with R-shears. This concept involved drilling and firing fans of blast holes aligned along R-shears. The aim was to break offsets, steps and bridges, thereby reducing the residual shear strength of the structure, and allowing a portion of the structure to move and partly destress. However, there are issues with this approach, including mining in broken ground, uninitiated explosives, and sufficient and accurate drilling along unknown R-shear undulations.

- Conventional SLC mining from north to south. This concept relies only on the seismic character observations given in Table 2. It does not have the assurance of the TSB approach.

The proposed TSB slot for ROB5 is positioned as shown in Figure 1. Two variations for the TSB slot were considered:

- A single continuous long slot. This slot would extend the full north-south length of the orebody. The slot would need to be tight-fired (in stages) for about $180 \mathrm{~m}$. There would need to be limited controlled mucking to loosen the brow between blasts, and this could be difficult. The slot would be progressively fired across each R-shear, to isolate it and encourage shearing. If anything went seriously wrong (bridged, frozen, loss of toe), further drilling and blasting or even a new raise may be needed to continue the slotting.

- Multiple slots and raises. Raises would be mined on or near each of the main R-shears with slotting from each raise halfway to its two adjacent raises. Each slot would cross one of the R-shears. The raises would allow minor destressing on the R-shears prior to slotting, and the blast void could be better controlled. Shearing could initiate during a raise firing, which may damage the remaining raise blastholes. The long slot option avoids this problem. Because the R-shears dip steeply, each raise will be positioned at say $>5 \mathrm{~m}$ from its R-shear, to avoid leaving small burst-prone wedges against the shears.

\section{PROPOSED IMPLEMENTATION IN ROB5}

Following the technical study, and to gain confidence in blasting and monitoring aspects of TSB, the proposal for applying TSB to ROB5 commences with two trials: 
- Trial of electronic detonation of a slot. A 13 Level slot is to be tight-blasted and rapidly-blasted using electronic detonation. The slot is between the south end of the CS3 stope and Reward Fault, a distance of $20 \mathrm{~m}$. The aim is to assess blast design, electronic detonation (new to Charlotte) and expansion void aspects. It is in a location where seismicity could occur, but at this shallower depth the seismic risk is low. This slot is scheduled for firing in October 2004 This trial will help establish the correct hole spacing, powder factors and timing parameters.

- Trial of slotting on 25 Level. Remote slot downholes will be drilled from a well-supported 24 Level east side access drive. Mucking would be from 25 Level. Slotting by using up holes from 25 Level is not practical because the retreating brow would be highly stressed, and the occurrence of R-shear movement - the object of the procedure - may damage the 25 Level access.

An ideal trial slot location is available at the southern-most end of the proposed slotting, between R5-shear and the current stope. Here the rockmass is already destressed, so practical problems with the TSB technique could be resolved without the threat of seismicity, yet al.l other conditions are the same as for the critical slotting. The trial will include a compre-hensive instrumentation program, including:

- Seismic monitoring - dense local seismic array to quantify controlled energy release.

- Measurement of the current stress state of the ROB5 remnant, followed by monitoring of stress changes during slotting and mining.

- Shear movement on structures.

- Smart cables in development to monitor loading of ground support in damaged ground.

If this field trial shows that the TSB technology is viable, full application of TSB to the ROB5 remnant will proceed.

\section{RISK ASSESSMENT OF TSB IMPLEMENTATION}

A risk assessment of TSB implementation raised the following concerns:

- Raise seismicity. Seismicity during development of the uphole raises (if used) is expected to be local and occur with blasts. If a raise is lost, however, a replacement raise will be needed.

- Slot seismicity. Seismicity could occur too soon during slot firing, before completion of the slot. This can be avoided by firing rapidly with electronic detonation.

- Slot frozen. The slot could become frozen due to a very tight blast. The technical design of the slot blasts must be precise and controlled.

- Bridged or poorly blasted section of slot. Bridges will be very highly stressed and could fail seismically later. A technical study of slot and blast design is required.

- Slot not a complete stress cutoff. The slot must connect to the base of the existing ROB5 void, to avoid significant stresses between the top of the slot and ROB5 stope.

- Seismicity during shift. Risk reduction strategies include dynamic cable support, remote drilling, and shotcreting at the fault intersections.

- Stress redistribution on other unknown structures. Currently unknown structures which intersect the final ROB5 void could move seismically.
- No R-shear response. R-shears could lock and refuse to move sufficiently when the slot is fired. There are several scenarios:

- If it is due to part of the slot being frozen, it is a major problem as noted above.

- If it is because the R-shear has previously moved and destressed, it is of no consequence. Measuring and monitoring stresses will indicate if this is the case.

- If it is because the R-shear is still locked, there is the potential for future seismicity. The best strategy would be to move on to the next slot blast.

\section{DAMAGE AREA AND SEISMIC OBSERVATIONS FOR BACK-ANALYSIS}

A key part of the technical study of the TSB concept was to forecast what seismicity reduction could be expected and under what constraints. Before numerical modelling could be applied to simulate the proposed TSB works, calibration was necessary.

Four significant fault-slip events had previously occurred in or near ROB5 stope. These were back-analysed to calibrate the model with actual behaviour. Table 3 summarises observed fault-slip areas associated with each event.

\subsection{Back-Analysis Event Descriptions}

The $\mathbf{R} 5$ event (28/1/95, Richter magnitude 2.8). This occurred during the first 25 Level production blast comprising two uphole rings breaking 13,000 tonnes of rock, with maximum charge per delay of $530 \mathrm{~kg}$. The blast extended the stope void northwards to intersect R5-shear. This shear had previously been exposed above 24 Level in the old stope, so the blast increased its dip exposure by about $30 \mathrm{~m}$. The event caused slip on R5-shear, with damage on 24 and 25 Levels (Fig 6). Damage was mainly confined to the southeast side (the stope void side) of R5.

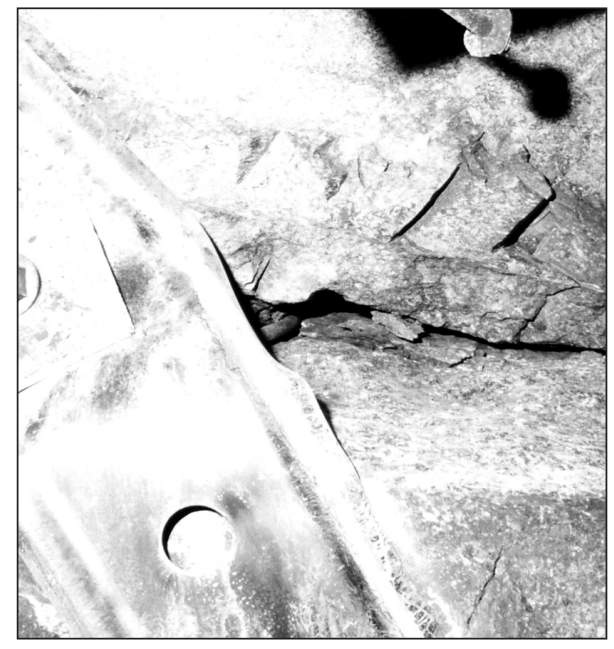

FIG. 6 Observed $30 \mathrm{~mm}$ slip where R5-shear crosses the 24-25 Level ramp (bolt in photo centre is offset to the left of the bolt hole)

The R3 and R4 events (17/3/97, Richter 2.3 and 2.6). Development of the new 2435 sublevel to access the unmined ROB5 resource between 24 and 25 Levels started in late 1996. The area experienced seismicity during development, and it is now known that the development had reduced the local mine stiffness by forming thin pillars to the 24 Level above and the 25 Level below.

These pillars were cut by R3-shear. Stress-driven yielding of the thin pillars started gradually as the development opened 
up an exposure on R3-shear. On 17/3/97, one month after the last development firing in the area, these two seismic events occurred without warning a minute apart. The first event is thought to have caused slip on R3-shear, and the second event on R4, with damage on 24 and 25 Levels. Damage was mainly on and to the southeast side of R3.

The Flanagan event $(27 / 6 / 98$, Richter 3.5). This event occurred towards the end of the S2 stope production mass blast. The blast broke 150,000 tonnes of rock to complete the northward advance of the S2 open stope.

An event location was suggested on Flanagan Fault about $50 \mathrm{~m}$ northwest of the S2 stope on 25 Level, however the seismic waveforms were clipped making this information inaccurate. The S2 stope blast appears to have progressed the undercutting of Flanagan Fault to the point where slip could occur. The strike length of Flanagan Fault between Charlotte and Reward Faults is $550 \mathrm{~m}$. Prior to this blast, the northern $300 \mathrm{~m}$ of Flanagan was exposed and unconfined by mining of the I1, I2 and S1 stopes. The S2 blast removed much of the remaining support to Flanagan, allowing the event to proceed.

\subsection{Back-Analysis Event Source Parameters}

Seismic monitoring system data for the four back-analysed events is included in Table 3. Richter Magnitude $\left(m_{R}\right)$ was computed from the seismic moment, and is the parameter recorded by GA (Geoscience Australia), measured remote from the source. Local Magnitude $\left(\mathrm{m}_{\mathrm{L}}\right)$ which is used by most mine seismic systems is also computed from the seismic moment. It varies between mines and systems and is measured comparatively close to the source.

For seismic events at Mt Charlotte, empirical comparison of GA and PSS measurements has yielded (albeit with considerable scatter):

$$
\mathrm{m}_{\mathrm{R}}=1.5+0.8 * \mathrm{~m}_{\mathrm{L}}
$$

TABLE 3 Observational and Source parameter data for the seismic events

\begin{tabular}{|c|c|c|c|c|}
\hline Event & R5 & R3 & R4 & Flanagan \\
\hline $\begin{array}{l}\text { Estimated fault } \\
\text { slip area } \mathrm{m}^{2}\end{array}$ & 25,000 & 8,000 & 8,000 & 70,000 \\
\hline Local $^{\star}$ Magnitude $m_{L}$ & 1 & 1.1 & 1.56 & 2.47 \\
\hline $\begin{array}{l}\text { Richter }^{*} \\
\text { Magnitude } \mathrm{m}_{\mathrm{R}}\end{array}$ & 2.8 & 2.3 & 2.6 & 3.5 \\
\hline $\begin{array}{l}\text { Seismic Moment } \\
\mathrm{Nm} \times 10^{9}\end{array}$ & 160 & 540 & 1,100 & $16^{* *}$ \\
\hline Seismic Energy MJ & 0.94 & 2.3 & 9.9 & $0.03^{\star \star}$ \\
\hline Source Radius m & 45.6 & 54.6 & 76.4 & $66.6^{\star *}$ \\
\hline \multicolumn{5}{|c|}{$\begin{array}{l}\text { * The Richter magnitude shown is as monitored by GA, and the local } \\
\text { magnitude as provided by the mine's seismic monitoring system. }\end{array}$} \\
\hline \multicolumn{5}{|c|}{$\begin{array}{l}\text { ** This event had a clipped waveform record, hence inaccurate } \\
\text { seismic source parameters. }\end{array}$} \\
\hline
\end{tabular}

\section{BACK-ANALYSIS OF PREVIOUS SEISMIC EVENTS}

The numerical modelling was done by AMC (2004) using the linear elastic version of the 3D boundary element code Map3D. The aim was to associate fault-slip energy release to event magnitude. A model for each seismic event was constructed, and included significant mining geometry and mining sequence leading to the event. Faults were represented in all the models initially by simple results planes, and then by the more complex displacement discontinuity elements with a pre-defined peak and residual Mohr-Coloumb constitutive model. The model results in this paper are those for the displacement discontinuity element versions.

The fault strength in the models was varied until the observed and numerically computed fault slip areas matched. Significantly, excellent estimates of fault-slip area were recovered by applying the previously estimated peak strength values for Mt Charlotte structures.

Modelling forecasts are considered to be worst-case due to the following four assumptions:

- All the energy release in any single event is due to slip on only one fault.

- Fault slip associated with a particular mining step occurs at one time, rather than in several episodes.

- Energy changes associated with mining before an event are stored as strain energy on the fault, to be released instantaneously at the time of the event.

- The rockmass acts linear elastically, i.e. the result is not a function of the path or sequence.

Two methodologies were used to compute the energy changes associated with plastic fault slip:

- Methodology 1: at a particular mining step a fault (displacement discontinuity element) is selected to move from its peak to residual strength. The energy changes associated with this strength change are found by computing the work done by the loading system on the displacement discontinuity element, through the LERD calculation method.

- Methodology 2: at a particular mining step a fault (displacement discontinuity element) is selected to move from its peak to residual strength. The ride and fault slip area associated with this reduction in strength are used as inputs into the Brune Model to determine seismic moment, which is then used to estimate energy through the Mt Charlotte MomentEnergy relations.

Overall the back-analysis work was considered to be successful because:

- Estimates of measured/inferred fault-slip have reasonable agreement with numerical model forecasts.

- The location and magnitude of the observed events is mimicked in the models.

- In each case, the models appear to explain the observed stick-slip mechanism of the fault slip event, i.e. energy storage on the faults as mining progresses, followed by disturbance and energy release.

Figure 7 and Table 4 present the four back-analysed events in terms of Richter magnitude, and the observed and modelcomputed fault slip areas. Figure 7 also shows a theoretical magnitude-fault slip area relationship based on work by Jager and Ryder (1999) who describe a simple relation for Local Magnitude $(M)$ versus event source diameter $\left(L_{s}\right)$ routinely used in Deep South African gold mines:

$$
\log _{10}\left(\mathrm{~L}_{\mathrm{s}}\right)=1+\mathrm{M} / 2
$$

From equations [1] and [2] the relationship between slip area, radiated energy, seismic moment and event magnitude is as shown in Figure 7. A reasonable correlation is evident in Figure 7 between modelled and observed slip areas. The shape of the best-fit curve to the observed data is similar to, but below the Jager \& Ryder theoretical relationship, and this difference is thought to be a function of different seismic monitoring systems and computations. 


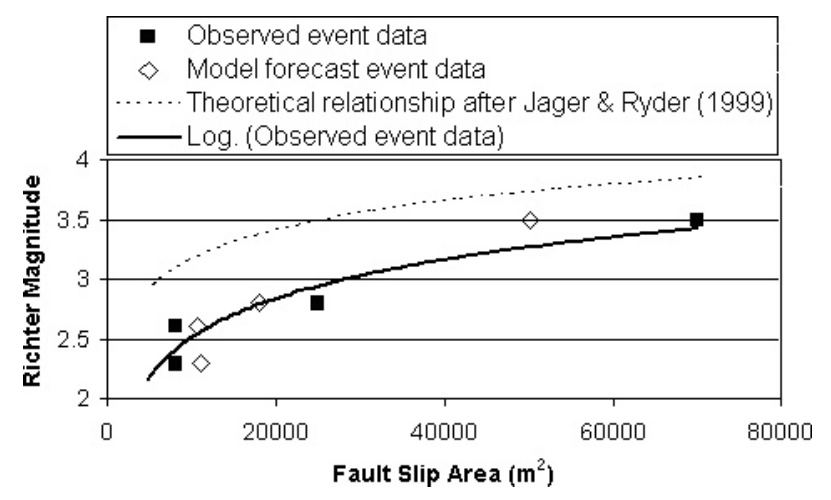

FIG. 7 Magnitude versus observed and model forecast fault slip areas for the four back-analysed events, compared to the theoretical magnitude-fault slip area relationship based on Jager and Ryder (1999)

TABLE 4 Comparison of Observed and Back-analysis Model Event Data

\begin{tabular}{lllll}
\hline Event & R5 & R3 & R4 & Flanagan \\
\hline $\begin{array}{l}\text { Observed Richter } \\
\text { Magnitude }\end{array}$ & 2.8 & 2.3 & 2.6 & 3.5 \\
\hline $\begin{array}{l}\text { Observed slip } \\
\text { area }\left(\mathrm{m}^{2}\right)\end{array}$ & 25,000 & 8,000 & 8,000 & 70,000 \\
\hline $\begin{array}{l}\text { Modelled Richter } \\
\text { Magnitude }\end{array}$ & 3 & 2.6 & 2.6 & 3.3 \\
\hline $\begin{array}{l}\text { Modelled slip } \\
\text { area (m²) }\end{array}$ & 18,000 & 11,000 & 10,500 & 50,000 \\
\hline $\begin{array}{l}\text { Modelled elastic } \\
\text { strain energy } \\
\text { release (MJ) }\end{array}$ & 7.9 & 4.7 & 4.3 & 33 \\
\hline
\end{tabular}

\section{FORWARD ANALYSIS TO FORECAST ROB5 SEISMICITY}

The ROB5 TSB proposal was numerically modelled firstly as a baseline reference case, and then with variations. A model of the proposed slot geometry was constructed, closely imitating development and stope locations, and including $\mathrm{R}$-shears and other faults. The mining was broken down into 19 steps. A key variable is the amount of damage induced by the TSB process, so two TSB options were studied:

- TSB Option 1: TSB rockfill with modulus $\mathrm{E}_{\mathrm{s}}=6.5 \mathrm{GPa}$ (i.e. $10 \%$ of rockmass E).

- TSB Option 2: Conventional slotting without rockfill, $\mathrm{E}_{\mathrm{s}}=0$ (fully destressed).

The incremental changes in fault-slip area were plotted as a function of mining step geometry, for R2, R3A, R3, R4, R5, Shea Fault and Reward Fault. All options assumed a south to north progression of mining for both the TSB zone, and the subsequent remnant mining. Figure 8 summarises the results for some of the various modelled options.

Modelling revealed the following trends:

- In TSB Option 1 (TSB, $\mathrm{E}_{\mathrm{s}}=6.5 \mathrm{GPa}$ ) the increased confinement results in less incremental fault slip, and a more controlled energy release, assuming fault slip occurs at the time of slotting, rather than during the mining phase.

- In TSB Option 2 (conventional slotting, $\mathrm{E}_{\mathrm{s}}=0$ ) complete destressing of the slot results in substantial and rapid increases in fault slip, in particular on R2-shear.

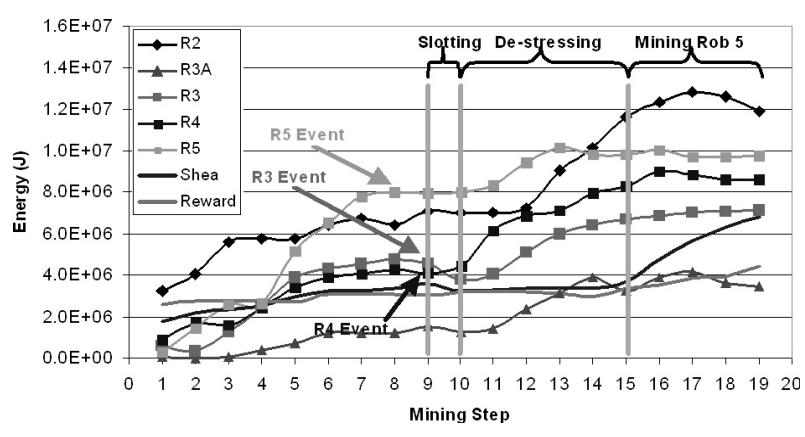

(a) worst fault behaviour

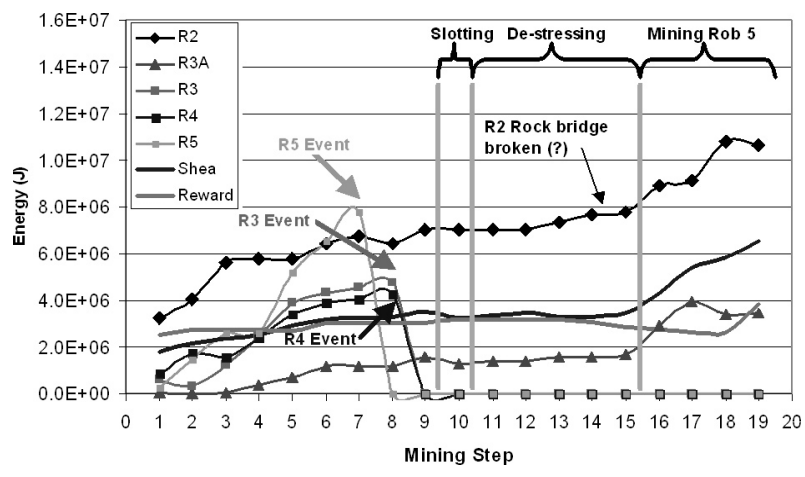

(b) best fault behaviour

FIG. 8 Modelled energy accumulation and release on each critical structure at successive mining steps, for the following example scenarios: (a) worst fault behaviour - if fault slip does not occur at all during the TSB procedure; (b) Best fault behaviour - fault slip occurs on exposure, and is restricted by $6.5 \mathrm{GPa}$ modulus slot rockfill

- There is clearly an increasing potential for strain energy storage on Reward Fault and Shea Fault, which are not managed by the TSB zone, being outside its influence. Therefore, other strategies are needed to manage seismic hazard associated with these faults.

The data showed that substantial and rapid increases in energy are forecast for all faults, in particular on R2 (refer examples in Fig. 8). It is assumed that R3, R4 and R5 have already largely destressed and can no longer behave in a significant stick-slip manner, and also that there are no unknown R-shears. R2 has the most significant energy accumulation, and is the main seismic hazard to be addressed. The rapid increase in energy accumulation during the formation of the TSB zone is also demonstrated and is marked as "destressing" in the diagram.

\section{FORECAST SEISMIC EVENT MAGNITUDES DURING MINING}

Model forecasts for event Richter magnitudes are as shown in Table 5. Seismic event magnitudes were calculated from the energy release data for best and worst cases. The best case assumes that energy changes occur at the "planned" times, i.e. during the slotting phase. The worst case assumes that the faults stick initially, and slip at the worst possible time, at the end of mining when the stored strain energy is largest. In Table 5, no change is apparent for Reward and Shea faults because these faults are outside the influence of the TSB works. Given the intractable nature of stick-slip seismic behaviour, these magnitudes are viewed as forecasts rather than certainties. 
TABLE 5 Forecast seismic event magnitudes from model results

\begin{tabular}{|c|c|c|c|c|c|c|}
\hline \multirow[b]{2}{*}{ MODEL CASE } & \multicolumn{2}{|c|}{ Worst fault behaviour - comparison } & \multicolumn{4}{|c|}{ Best fault behaviour - comparison } \\
\hline & Open slot model & TSB model & $\begin{array}{l}\text { Reduction in } \\
\text { energy release } \\
\text { due to TSB }\end{array}$ & Open slot model & TSB model & $\begin{array}{l}\text { Reduction in } \\
\text { energy release } \\
\text { due to TSB }\end{array}$ \\
\hline $\begin{array}{l}\text { SLOT ROCKFILL } \\
\text { MODULUS }\end{array}$ & $E_{s}=0$ & $\mathrm{E}_{\mathrm{s}}=6.5 \mathrm{GPa}$ & & $E_{s}=0$ & $\mathrm{E}_{\mathrm{s}}=6.5 \mathrm{GPa}$ & \\
\hline $\begin{array}{l}\text { SLOT SHEARING } \\
\text { ARREST } \\
\text { CAPABILITY }\end{array}$ & Nil - open slot & $\begin{array}{l}\text { Shear resisted by } \\
\text { tight packed rock } \\
\text { in slot }\end{array}$ & & Nil - open slot & $\begin{array}{l}\text { Shear resisted by } \\
\text { tight packed rock } \\
\text { in slot }\end{array}$ & \\
\hline FAULT BEHAVIOUR & \multicolumn{2}{|c|}{$\begin{array}{l}\text { Fault sticks till maximum energy } \\
\text { accumulated }\end{array}$} & Percent & \multicolumn{3}{|c|}{ Fault slip as soon as exposed } \\
\hline R2 event & 3.0 & 2.8 & 50 & 1.6 & 1.5 & 29 \\
\hline R3A event & 2.1 & 2.0 & 29 & 1.6 & 1.3 & 65 \\
\hline R3 event & 1.5 & 1.0 & 82 & No event & No event & $\mathrm{N} / \mathrm{A}$ \\
\hline R4 event & 2.0 & 1.5 & 82 & No event & No event & $\mathrm{N} / \mathrm{A}$ \\
\hline R5 event & 1.8 & 1.4 & 75 & No event & No event & $\mathrm{N} / \mathrm{A}$ \\
\hline Reward event & 2.6 & 2.6 & 0 & 2.6 & 2.6 & 0 \\
\hline Shear event & 2.8 & 2.8 & 0 & 2.8 & 2.8 & 0 \\
\hline
\end{tabular}

\section{CONCLUSIONS}

It is considered that a viable plan to mine the ROB5 remnant would be based on two key strategies:

- Mining direction north-to-south, to take advantage of the directionally-related behaviour of the major structure systems.

- Mining with the TSB technology, to control the seismic response.

Assuming a successful TSB implementation, a significant reduction in seismic risk is anticipated. The peak seismic magnitude of Richter 3.0 in the worst case is forecast to drop to 2.8 solely by implementing TSB. This 0.2 magnitude reduction represents a $50 \%$ reduction in energy release. The model assumptions mean that the forecast improvements are considered to be conservative.

The back-analysis modelling work demonstrated a good correlation with underground observations, and on this basis the model forecasts are regarded as valid, and an encouragement to pursue the TSB concept further. The success of the TSB depends on the degree of damage achieved, the induced fault slip, and the potential for reloading during mining, all of which are difficult to estimate. Further work is needed, covering aspects including ground support requirements for development works, design of monitoring systems to track fault destressing, and firing designs for the TSB zone.

It is hoped to trial the technique in the near future. Benefits of a successful TSB implementation include:

- Recovery of ROB5 reserve with low seismicity.

- Experimental verification of the TSB technology.

- Support for the current understanding of seismic principles affecting Mt Charlotte.

- Availability of the TSB method for future mining at Mt Charlotte and elsewhere.

\section{ACKNOWLEDGMENTS}

The authors wish to express their appreciation to KCGM and AMC for permission to publish this paper, and to all those who played a part in the ROB5 story so far.

\section{REFERENCES}

AMC Consultants (2004) Seismic Analysis of ROB5 Destressing. Consultant Report No 204048 for KCGM Mt Charlotte, June.

Gibowicz, J. and Kijko, A. (1994) An introduction to mining seismology. Volume 55, Academic Press, London, pp. 241-248.

Hudyma, M.R., Heal, D. and Mikula, P.A. (2003) Seismic monitoring in mines - Old technology, new applications. First AGCM Conference, Nov. pp. 209-226.

Jager, A. and Ryder, J. (1999) A handbook on rock engineering practice for tabular hard-rock mines. SIMRAC, Braamfontein.

Lee, M.F. and Fotakis, D. (1992) Charlotte Deeps: 29 Level Virgin Stress Measurement. James Askew and Associates, JAA 1724

Mikula, P.A. and Lee, M.F. (2002) Forecasting and controlling pillar instability at Mt Charlotte Mine. Deep and High Stress Mining - First International Seminar. Australian Centre for Geomechanics, Nov 2002. 